\title{
O ENTRETENIMENTO DA NATUREZA
}

Rodrigo Santos Cruz ${ }^{1}$

Ultimamente, tenho me demandado tanto. Chego a imaginar que toda essa vontade de me realizar esteja errada e que algo deva ter acontecido para que em algum ponto pelo qual passei ou, até mesmo respirei, provocou um pré-requisito exagerado e que não cabe na minha forma, na minha forma comum e pobre, no meu desejo comum e pobre. Então, reflita comigo: como um trem pode andar sem uma linha férrea? Em algum momento eu me distraí, mas não teria sido a distração de perder a hora de ir para o trabalho ou de esquecer o aniversário de um ente querido. Eu poderia ficar elencando tantas situações “distraíveis", e, ainda assim, não conseguiria expressar o quão extremo fora meu devaneio, se é que existiu.

Desde então, não consigo refutar o simbolismo simples que me ocorre: as horas de uma tarde, o olhar dos estranhos na rua, uma pessoa que solicita algo alhures. Está aqui, amontoado em mim, como se eu fosse um recipiente, que furta o senso alheio e se torna um cálculo humano impossível de ser respondido. Se eu pudesse dormir e sonhar com tudo que me ocorrera, talvez eu chegasse ao ponto pelo qual passei a não consegui me desfazer do julgamento que ponho e involuntariamente me condiciona. Condiciona a quê? Tudo por conta de um enredo? Eu era alguém desprovido de um enredo e, ao pedir, ganhei tantos enredos que agora não consigo me desfazer do olhar dos cães que vagam na minha rua? Como se alcança um modo de pôr a vida numa forma possível e amena, igual a vida de uma pessoa que outrora sonhou com algo, mas conseguiu objetivar a vida novamente e ver que simplesmente sonhou? Qualquer vislumbre possível retardou tanta coisa.

Certa vez, quando ainda podia ir aos lugares sem conjecturar o absurdo dos outros não se questionarem, encontrei uma árvore repleta de castanholas. Aqui chamam de castanholas e é o que importa, até por que já é uma informação relevante para saber de que árvore estou tratando. Apesar disso, não pretendo entrar nessa discussão taxonômica ou, até mesmo, de idiossincrasias regionais quanto ao nome mais aceito, uma vez que me parece perturbador e prefiro me ater ao fato da sombra que recebi como dádiva daquela árvore.

Nessa época, eu tinha uma bicicleta. Hoje dirijo um automóvel que, por incrível que pareça, não me leva a lugares sombreados, embora seja um carro coberto o que, de certa forma, acaba compensando. No senso comum, sabe-se que carros conversíveis custam muito caro e você

\footnotetext{
${ }^{1}$ Graduado em Ciências Sociais (UFPI). Mestre em Ciência Política (UFPI). Professor do Instituto Federal de Educação, Ciência e Tecnologia do Piauí (IFPI), campus São Raimundo Nonato (PI). E-mail: rodrigosantoscruz1989@gmail.com
} 
não tem sombra, mas pode ter, se quiser. Da minha parte, essas prerrogativas de consumo não são possíveis, desejáveis e nem sei se um dia serão, uma vez que no meu planejamento corrente não consta obter um carro desse modelo.

Apesar de tudo, quando fazia meus percursos de bicicleta na adolescência, fui levado a vários lugares, tanto ensolarados, quanto sombreados e, mesmo com hipossuficiência financeira, eu lia nos livros da escola que andar de bicicleta era uma atividade saudável para o organismo. Daí, surgia um conforto tão inocente, que eu chegava a romantizar a pobreza, embora somente eu, no meu círculo de amizades julgasse assim. Os outros viam aquele meio de transporte de uma maneira arcaica e estigmatizavam seus usuários. Eu tinha pressa e compromissos, então, mesmo a caminhada constituindo também uma atividade saudável, muito provavelmente eu me atrasaria para minhas frugais ocupações, pois a preguiça e a desorganização sempre foram muito presentes no meu comportamento, algo condenável pelos familiares até hoje.

Naquele dia, domingo, parei do lado daquela árvore, pus o tripé da bicicleta para que esta ficasse firme no asfalto e encostei a parte dorsal do meu corpo no tronco áspero e grotesco do pé de castanhola. Havia muitos cupins no seu caule. Desconfiado, durante alguns minutos imaginei que alguém pudesse sair de uma das casas e ver aquela cena e perguntar o que sucedia ali. Rapidamente, concluí que ninguém faria isso e senti que expulsava a vontade do passeio na rua. Será? Que passeio? Aquilo que eu estava fazendo ali era um passeio? Fico arrependido por não ter me prolongado nesta aventura e assim eu saberia ou, pelo menos, teria uma noção razoável: qualquer indício de rua tumultuada e concomitante a minha presença naquele lugar me daria mais sossego, me forneceria um alívio, uma boa noite de sono, aqueles sonos das pessoas que não questionam.

$\mathrm{Na}$ ânsia de fugir, eu encontrei sossego, mas esse era o intuito? Ali tudo me inquietava, então chorei. Deitei sobre as folhas secas, repletas de formigas e castanholas, que exalavam um odor azedado, estavam podres. Como isso era o sossego? Então, eu não poderia requisitar a quietude? Mas, sequer problematizei algo! Como pudera me sentir perturbado e desviado, se nem ao menos eu pude ver os outros que ali viviam para aí sim, talvez, elaborar um parâmetro? Foi nesse momento, que me arrependi mais ainda por ter permanecido pouco tempo ali, e o arrependimento é como uma sede em mim, quando percebo, estou arrependido, embora na maioria das vezes, eu não saiba do que se trata essa perturbação ou epifania.

No tempo que permaneci ali, fiquei sujo de terra e comecei a ter urticária das folhas secas e das mordidas das formigas. Sim, as formigas têm boca. Acredito que eu esteja correto, pois é um ponto sobre o qual os entomólogos estabeleceram um consenso: chamam isso de paradigma e 
publicam em revistas sérias e no fim as pessoas aceitam, pelo menos por um tempo. Você já viu alguém contestando que as formigas não possuem um órgão semelhante a uma boca?

Eu estava imundo e ninguém apareceu: por um instante, achei relevante o estado da minha higiene corporal, a tal ponto de isso ser motivo para chamar a atenção de alguém. A sujeira daquela árvore deveria ser preocupação para os que moravam ao seu redor? E a minha sujeira? A quem eu deveria reportar? Não era a sujeira do lixo humano, o que a meu ver era raro; era na verdade uma preocupação com os cupins. Talvez este último fato fosse extremamente relevante: não se pode desconsiderar que cupins acabam migrando para a madeira que sustenta os telhados, então pensei na imensa indiferença alheia reinando perto de mim. Quanta gente deveria estar dormindo e nem ao menos sonhava com os cupins nas ripas e caibros dos telhados de suas casas? Seria um evento grave da vida ordinária para se prevenir em um domingo? Durante a semana, a preocupação estaria concentrada no sustento da prole - muitas vezes indesejada -, na manutenção dos víveres essenciais, supérfluos, no fornecimento de eletricidade, na limpeza dos cômodos etc. Domingo não! Domingo não era dia de sair de tanto conforto da casa para mapear o rastro de cupins!

Deitado ali sobre as folhas, vejo um homem bem idoso passando. Notei que carregava em uma das mãos uma pequena sacola amarela, deixando à mostra a ponta de um rolo de fumo. $\mathrm{O}$ idoso tinha a marcha já bastante lenta e foi se aproximando de mim, ao mesmo tempo em que tossia bastante. Logo, minha expressão facial mudou para uma cara de nojo. Como eu poderia ficar com nojo? Eu estava deitado no chão e sujo! Mas sim, fiquei com nojo. Ele me ofereceu ajuda, supunha que eu estava em perigo. Mal sabia que eu estava em regozijo pela indiferença do mundo e somente alguém no fim da vida notou. Não meu prazer, mas minha indiferença. Então, é preciso estar próximo do fim da vida para entender a fuga? Os doentes em situação de tratamento paliativo, nessa perspectiva, são sortudos? Como aquele homem fraco, de marcha lenta e fumante poderia me auxiliar, se pela sua imagem eu poderia the fornecer mais amparo do que ele poderia supor? Eu poderia? Então, neguei com a cabeça seu auxílio e ele foi embora me xingando. Nesse momento, tive a certeza de que ninguém poderia me ajudar.

Já havia passado três horas de relógio e me veio a ideia de que pôr uma corda em um dos galhos caídos no chão e amarrar num galho da árvore para fazer um balanço seria uma forma de chamar atenção, mas eu não tinha corda alguma, tampouco pretensão de bater na porta de qualquer casa para solicitar isso. De qualquer forma, é sabido pelos botânicos que aquela árvore possui galhos frágeis e leves, apesar de que no passado, diante dessa desvantagem ou não, sua madeira fora utilizada para fabricar canoas na antiga Polinésia. O fato é: nesse meu intento de construir um balanço, eu estaria muito provavelmente suscetível a uma queda. Daí pensei: outra? É possível cair mais ainda? Pelo visto, sim. Há desastres, como quedas, os quais não ferem seus músculos ou ossos, 
alguns machucam sua essência e não há medicina que resolva, há somente choro na madrugada ou em qualquer momento, como agora eu estava: chorando. Como é possível? O que me afligia era aquela árvore? Eu estava inconformado porque até a sombra que me oferecera era uma sombra repleta de formigas e folhas ásperas que me deram uma coceira infeliz? Fiquei todo avermelhado, rubro, eu vi, estava com a pele encarnada: olhei meus braços e barriga e as unhas grandes não ajudaram, acabei me ferindo, sim, mais uma vez. Isso vai parar?

Eu pensei que jamais estaria numa posição tão confortável com minha carne toda coçando e, além de tudo, imaginava a vida do idoso que se atrevera a me ajudar! Será se ele queria tirar meus planos? Será que naquela sacola, além do rolo de fumo, conteria também algum alucinógeno que me levaria até onde eu precisava? De toda forma, recusei com veemência circunspecta, como quando uma criança rejeita uma nova amizade por pura timidez. Vergonha não me faltava. Quando me perguntavam o que eu gostava de fazer nas horas vagas eu ficava tímido, não porque fosse uma criança que sofrera uma má socialização - embora sim -, mas pelo fato de não ver hora alguma preenchida. As horas em si eram vazias e eu as preenchia? Como isso era possível? Elas tomavam forma quando eu, nas minhas atividades triviais, punha um objeto em outro lugar? Como eu saía dessa situação constrangedora provocada por esses questionamentos absurdos? $\mathrm{Na}$ impossibilidade de responder com alguma firmeza, simplesmente dizia que andava de bicicleta. Todos acabavam rindo com escárnio dessa resposta, pois supostamente o lazer que praticavam era muito mais rico de ocupações, assim enchiam o peito de vaidade. Ali residia o próprio entretenimento!

De certo, acho que inconscientemente sempre aceitei que minha agenda nunca fora muito cheia. Como preencher o tempo, se ele era traiçoeiro? Eu deveria tirar-lhe do seu vácuo e fornecer meu labor e assim o tempo estaria contente, mas, ao mesmo tempo, estaria numa tocaia para zerar meu empenho e retroceder meu dispêndio? Não poderia chegar tão perto dessa conclusão, jamais! No entanto, quando das risadas sobre meu lazer, eu fingia que meus itinerários como ciclista eram interessantes e os enfeitava com mentiras convincentes. O olhar dos incomodados aos poucos se alterava até transparecer uma aceitação de que supostamente eu poderia preencher as horas de lazer daquela forma. Mas não! Ainda estava em mim e não importava o quanto eu mentisse. Eu precisava era de um conselho ou dois!

Suponho com uma certeza substancial, que nunca soube fornecer conselhos ou soluções - até mesmo simples - para os problemas alheios. Ninguém me procurava e isso era um alívio! Sabiam desse meu fracasso ou qualidade. Como alguém poderia confiar suas esperanças nas esperanças alheias? Tanto absurdo ocorria ao meu redor e no fim eu só ouvia como um homem que fora pego traindo a esposa e acaba tendo que engolir os sermões morais do cônjuge, consciente o adúltero que toda essa moralidade direcionada a ele é uma grande balela. Perdoem se acham que 
estou sexualizando meu enredo ou sendo machista. Os homens são adúlteros porque aprendem a ser e estão convictos que suas transgressões sociais configuram um fato banal. Eu sou homem, então tirem suas conclusões, logo qualquer dever moral está tão longe do meu senso prático. A moralidade se apresenta a mim como uma placa de trânsito, que fora posta ali para regular a via pública, mas o que de fato importa é decifrar o que ela pretende informar e isso sempre bastou. Seu papel simboliza em mim até esse ponto. No senso comum, eu poderia ser tachado de retardado: "Senhor, a placa indica que você não deve exceder a velocidade acima do que está posto na sinalização vertical”. Essa advertência soa em mim como uma mix de inocência e burrice, o que não implica muita incoerência, pois quase sempre associei inocência e burrice, em um mesmo conjunto de qualidades sinônimas.

No chão, onde fiquei por um tempo, pensei em seguir aquele idoso e falar-lhe sobre mim, sobre sua gentileza, sobre sua loucura ou talvez sobre sua falta de humanidade. Tal situação iria transparecer áspera com alguém, cujo discernimento estivesse já um tanto comprometido devido à idade. Possivelmente, ele jogasse aquela sacola em mim e gritasse pedindo ajuda, pois seria um fato extremamente inconveniente. Apesar de tudo, eu sentia que ele merecia um conselho. Um conselho meu? Jamais poderia fornecer qualquer direção sobre suas esperanças e condutas ou, até mesmo, sobre seu senso prático, o que tornaria mais absurdo. Ao invés disso, eu lhe pediria um conselho, algo bobo relacionado a cupins em pés de castanhola. Um homem naquela idade talvez pudesse esclarecer a melhor forma de conter pragas na zona urbana e ainda assim, mesmo essa informação especial para mim, não afetaria o mundo. Ou não? Agora dei de considerar inútil a vida dos cupins? Quem julgaria sua existência constante naquela árvore? O conselho daquele homem que mal se aproximou de mim? Eu confiaria tanta vida nas mãos dele?

Seria muito delicado, imprudente até! Já havia passado cinco horas de relógio e meu único espectador já estava longe. E, permanecendo ali, aquele tempo todo, concluí de maneira confusa, que que eu era de fato um produto da natureza, algo como a simplicidade e a ternura nunca antes imaginada, uma forma disforme e impossibilitada de interromper a vontade alheia. Eu tinha muito receio de cometer algo do tipo! Quando criança, na aula de Educação Física, a professora certa vez me obrigou a jogar futebol. Tímido e sem qualquer argumento aparente para refutar o comando, acatei. Durante o jogo com os colegas da turma, acabei caindo e quebrando o braço. A professora ficou desconfiada, como se eu fosse culpar sua conduta autoritária pelo ocorrido. Isso minha mãe fez, eu apenas acenei dando tchau com o braço bom. Ali percebi que a natureza era uma coisa boa e imprevisível e a qualquer momento eu poderia me quebrar todo e sentir a dor da vida, mas a dor da vida não era apenas a de um braço quebrado, era não aceitar as coisas, era a dor da professora que não sabia o que era machucar alguém, era a inocência, e agora, com remorso, ela sorria para 
mim e me dispensava das atividades nas suas aulas. Por isso, eu não confiava nos adultos, eles não sabiam que a natureza era verdadeira e se você impor sua arrogância ou inocência, você sentirá dor. Durante muito tempo, senti pena dela, até que mudei de escola e sua imagem foi aos poucos sendo desvencilhada do meu senso prático.

Mas sempre haveria essa tragédia imposta no meu caminho, feito um evento trivial que me privou de um desejo: o desejo de não praticar esportes. Isso era meu e foi tirado. Cheguei a pensar que Deus havia castigado aquela professora por ter feito meu desejo não ser cumprido. Na minha cabeça, Deus se ocupava de inúmeras tarefas e era como um despachante num serviço de protocolo. Não sei bem se qualquer desejo interrompido de forma injusta seria tão prontamente vingado por Deus. Talvez, só os desejos infantis ou de pessoas de alma formada, mesmo infantis. Jamais eu saberia, até porque não querer praticar futebol não me parece hoje um desejo. O desejo deve ser algo mais substancial, algo que caracterize a própria vida, fazendo dela, inclusive, uma nãovida, não no sentido biológico, mas no sentido da realização.

Não ser solidário na aula de Educação Física talvez não pudesse "des-realizar" a vida ou realizá-la e a vingança de Deus seria apenas pontual, porque o desejo em si interrompido causaria uma ira indescritível como se crê no mundo cristão quando no começo do mundo se comeu uma fruta que não era para ser comida, aí o desejo de Deus poderia ser um parâmetro da vingança, bem como seu teor. Mas vejam, de um lado eu também sofrera, no sentido comum da carne: havia quebrado o braço. A vingança só poderia ser compensada com a dupla interrupção das vontades? Além de não ter minha vontade respeitada eu deveria sofrer um castigo físico para engendrar no meu algoz uma consciência do mal que provocara a uma criança? Deus, além de sádico, seria a tal ponto tão desorganizado? Deus era sádico porque se vingava, mas de quem se vingava? De mim ou daquela mulher? A vingança era, na verdade, indirecionada e de fato a essência? Deus era cego?

Então, eu estaria agora procurando uma forma de poder me realizar? Eu queria algum mecanismo alcançável para poder fugir da sombra daquela árvore. Diante da infâmia do mundo, o que se merece é uma sombra de uma árvore cheia de pragas? Meu sossego não poderia ser mais perturbador! Talvez fosse esse o meu desejo: o sossego. Havia saído num domingo para um passeio que digo ser meu entretenimento e então, deparo-me com a vontade do sossego. Não sei como apareceu isso na minha frente, mas quase consegui tocá-lo, eu lembro! Parecia um lugar onde não se pedia nada, embora eu não consiga descrever, prezado. Você já foi em algum lugar assim? Por isso, não me amole, querendo que eu o descreva, pois não há como, uma vez que tal lugar não existe ao alcance do nosso modesto olhar. Então, é assim e pronto!

Como tudo na vida tem uma hora, eu precisava esperar o tempo certo? Então, quebrei meu braço porque esperava o tempo certo para que ocorresse? Alguém pode esperar por mim? 
Pode-se elaborar uma procuração de espera para uma vontade e mesmo assim não saber? Meu objetivo era somente esse sossego sem demanda e, infelizmente, ganhei uma árvore de tronco áspero numa rua vazia. Eu não queria aquela rua, aquela árvore, mas parei ali porque supus que o sossego ali se escondera. Quando me vi todo ferido de tanto me coçar, por conta das mordidas das formigas e das folhas secas, tive a certeza que jamais conseguiria me realizar. Eu poderia levantar e ir para outro lugar e, ainda assim, tudo seria pedido, eu pediria algo para mim mesmo, dessa forma nunca haveria a possibilidade do meu desejo de vida ser real.

Comecei a chorar novamente. Por um segundo, imaginei que meu braço quebrado havia sido uma forma de castigar a vilania de quem interrompe a indiferença do mundo que uma criança nutre, mas não! Eu quem sofrera, eu quem viu o quanto qualquer parte de mim poderia ser interrompida e ainda ser privado de me realizar, eu, uma criança! Imagina agora! Imagina agora, não é? Agora estaria interrompendo a vontade de alguém? Sim, eu estava: das formigas. De quem mais? Não saberia responder, mas me tornei o mundo, a matéria que ele precisa, parte numa engrenagem sádica que obstrui o alcance do desejo das crianças, dos adultos e, sem qualquer consideração, dos adultos senis, como aquele idoso que acabei por interromper sua piedade para comigo. Eu fiz isso consciente? Como vou saber? Mas, era algo concreto, descritível até esse ponto. O que tanto mais eu estava deixando que não se realizasse?

Eu poderia ser um óbice para meu próprio desejo? Tudo indica que sim. Como eu ficaria aliviado se conseguisse desvendar uma forma que, pelo menos de mim, pudesse driblar minha auto sabotagem e assim eu não mais me obstruiria. E os outros? Se não chego em mim, como vou chegar no alheio? Mesmo ali parado, fiz da vida daquele idoso um sentido menor, fiz dele um estorvo, e era um efeito irrevogável, mesmo que eu levantasse e tentasse alcançá-lo e falasse: eu aceito sua ajuda! Não! Ele talvez reconsiderasse, mas seria por impaciência ou por pensar que eu estivesse com pena dele e de fato eu estava, não pelo fato de ser um homem com a idade avançada, mas por estar a tantos anos sem saber que não poderia se realizar, ao mesmo tempo que eu sentia raiva, pois em igual proporção, ele deve ter caçado o desejo de alguém, pelo menos uma vez. 